\title{
Structure Modification upon Ultrasonic Processing of an AA4032 Piston Alloy: Comparison of Permanent Mold and Direct-Chill Casting
}

\author{
SUWAREE CHANKITMUNKONG, DMITRY G. ESKIN, \\ and CHAOWALIT LIMMANEEVICHITR
}

\begin{abstract}
Piston Al-Si alloys have very complex compositions and multi-phase heterogeneous structure, so it is necessary to control the formation of primary and eutectic compounds. In this study, the ultrasonic melt processing (USP) of a eutectic Al-Si piston alloy (AA4032-type) was performed in a permanent mold and during direct-chill (DC) casting to study its effects on the structure refinement and modification. The principal difference between these two ways of casting is that in the permanent mold the solidification front progressively moves towards the ultrasound source, while in the DC casting the position of the solidification front is fixed in space. The results showed that the USP can successfully refine primary $\mathrm{Si}$, Fe-containing intermetallics and aluminum grains. Refinement of primary $\mathrm{Si}$ was accompanied by the increase in its amount, which was attributed to both enhanced heterogeneous nucleation and fragmentation. The refinement of $\mathrm{Fe}$-containing intermetallics and $\mathrm{Al}$ grains resulted from the fragmentation mechanism and were more pronounced when USP was applied below the liquidus temperature in the permanent mold. However, the eutectic phases coarsened upon USP, and this effect was most pronounced when USP was applied to the semi-solid material. This was related to the strong attenuation of acoustic waves, which effectively heats the semi-solid material and induces corresponding coarsening of the phases. Acoustic streaming induced by an oscillating sonotrode affected the depth of the sump while simultaneously decreasing the macrosegregation, which reflects the dominant role of the melt flow directed against natural convection. The results demonstrated the importance of the solidification stage at which the USP was applied and the specifics of the USP mechanisms acting at the different stages of solidification.
\end{abstract}

https://doi.org/10.1007/s11661-019-05575-5

(C) The Author(s) 2019

\section{INTRODUCTION}

AA4032 alloys are widely used in engine parts in automotive industry because of their properties, i.e., light weight, thermal stability, good corrosion, and wear resistance. These alloys are usually produced into billet

SUWAREE CHANKITMUNKONG is with the Department of Production Engineering, Faculty of Engineering, King Mongkut's University of Technology Thonburi, 126 Pracha-Utid Rd., Bangmod, Tungkhru, Bangkok, 10140 Thailand and also with Brunel University London, BCAST, Uxbridge, Middlesex UB8 3PH, United Kingdom. Contact e-mail: suwaree.03@mail.kmutt.ac.th DMITRY G. ESKIN is with Brunel University London and also with Tomsk State University, Tomsk 634050, Russian Federation. CHAOWALIT LIMMANEEVICHITR is with the Department of Production Engineering, Faculty of Engineering, King Mongkut's University of Technology Thonburi.

Manuscript submitted August 26, 2019.

Article published online December 9, 2019 by direct-chill (DC) casting for subsequent processing such as extrusion or forging. The mechanical and service properties of these alloys depend on the presence of hard and thermally stable phase particles such as $\mathrm{Si}$, $\gamma-\mathrm{Al}_{7} \mathrm{Cu}_{4} \mathrm{Ni}, \quad \delta$ - $\mathrm{Al}_{3} \mathrm{CuNi}, \quad \beta$-phase $\left(\mathrm{Al}_{9} \mathrm{Fe}_{2} \mathrm{Si}_{2}\right)$, and $Q-\mathrm{Al}_{5} \mathrm{Cu}_{2} \mathrm{Mg}_{8} \mathrm{Si}_{6}$ phases $^{[1,2]}$ as well as on the phases that form precipitates upon annealing such as $\mathrm{Al}_{2} \mathrm{Cu}$ and $\mathrm{Mg}_{2} \mathrm{Si}$. Higher $\mathrm{Cu}$ and $\mathrm{Ni}$ concentrations are shown to be beneficial for high-temperature properties. ${ }^{[3,4]} \mathrm{On}$ the other hand, most of the particles of solidification origin, primary or eutectic, are rather brittle and, in the case of large size and/or elongated morphology, may act as stress concentrators in the structure, causing premature fracture or overall decrease in ductility and toughness. ${ }^{[5,6]}$ The morphology and size can be controlled by additions of some alloying elements (e.g., $\mathrm{Mn}$ for AlFeSi phases $^{[7]}$ or application of physical treatment (e.g., ultrasonic melt processing (USP) $)^{[8]}$ as well as modification of eutectics (e.g., by alkali-earth metals) ${ }^{[9]}$ which positively affects mechanical properties such as ductility and strength at a high temperature. The overall 
structure, i.e., primary aluminum grains, can be refined by an addition of AlTiB master alloys, ${ }^{[10]}$ which is not working very well in high-Si alloys, or by USP through a variety of mechanisms reviewed elsewhere. ${ }^{[11-13]}$ It is important that these mechanisms are working at the different stages of solidification, e.g., the activation of heterogenous nuclei-in the liquid state, while the fragmentation of dendrites-below the liquidus. ${ }^{[12]}$ Acoustic streaming flow is another interesting phenomenon that accompanies USP. Acoustic streaming flow can be potentially beneficial for dispersing the solid phase particles and redistributing the melt in the liquid and semi-liquid parts of the billet, affecting the structure uniformity and macrosegregation. ${ }^{[1]}$

USP has significant effects on the primary $\mathrm{Si}$ and AlFeSi phases, especially in hypereutectic Al-Si alloys with high $\mathrm{Fe}$ concentration. The suggested mechanisms included the acceleration of peritectic reaction transforming the $\delta-\mathrm{Al}_{3} \mathrm{FeSi}_{2}$ phase to the $\beta-\mathrm{Al}_{5} \mathrm{FeSi}$ phase and fragmentation of primary crystals. In addition, the acoustic streaming was shown to distribute primary intermetallics more uniformly in the treated volume. ${ }^{[14]}$ Grain refinement upon USP has been demonstrated on a number of Al-based hypo-eutectic alloys. ${ }^{[11,15]}$ For near-eutectic Al-Si alloys, the refinement of primary $\mathrm{Si}$ and some intermetallics have been reported. ${ }^{[16]}$ When it comes to the phases of the eutectic origin, the results of USP are controversial. On the one hand, there are data showing that the application of USP during solidification results in coarsening of an Al-Si eutectic, especially in treating the semi-solid material. ${ }^{[17]}$ On the other hand, there is an evidence that USP may result in refinement of an Al-Si eutectics when the primary grains have been significantly refined during continuous USP from the liquid into the semi-solid state. ${ }^{[18]}$ Therefore, this issue needs to be clarified.

The other significant issue that arises when one tries to compare the results of different works is that the experiments with USP are frequently done during solidification (e.g., References 19 and 20, with the resultant structure being a result of several mechanisms working sequentially and sometimes simultaneously ${ }^{[12]}$ ). Note the principal difference between these two ways of casting with regard to the ultrasonic processing, i.e., the solidification front progressively moves towards the ultrasound source in the permanent mold, while in the DC casting the position of the solidification front is fixed in space. Therefore, it is prudent to compare the results of USP for different casting conditions, keeping the alloy and USP parameters the same.

In this work, we aimed at exploring the differences in USP effects for two different casting methods. The first one is casting in a permanent mold with USP performed at different stages of solidification, and also at a relatively low cooling rate. The second one is DC casting which is of industrial interest and includes USP applied above and close to the liquidus at a relatively high cooling rate. The research is performed on an AA4032-type piston alloy containing a variety of structure constituents of interest, i.e., primary $\mathrm{Al}$ dendrites and Si crystals, primary and eutectic Fe-containing intermetallics, and complex eutectics.

\section{EXPERIMENTAL PROCEDURE}

Prior to casting, the experimental alloys were prepared in a clay graphite crucible in an electric resistance furnace from 99.9 wt pct pure $\mathrm{Al}$; 99.5 wt pet pure $\mathrm{Mg}$ and $\mathrm{Al}-45$ wt pet $\mathrm{Si}, \mathrm{Al}-45$ wt pet $\mathrm{Cu}, \mathrm{Al}-20$ wt pet $\mathrm{Ni}$, and $\mathrm{Al}-45 \mathrm{wt}$ pet $\mathrm{Fe}$ master alloys. The chemical compositions of the alloys were analyzed on samples taken from the melt by emission spectrometry and are given in Table I.

The ultrasonic equipment used in all experiments comprised a 5-kW ultrasonic generator (Reltec), a 5-kW water-cooled magnetostrictive transducer (Reltec), a conical $\mathrm{Ti}$ waveguide (65 to $40 \mathrm{~mm}$ in diameter), and a conical niobium* sonotrode (40 to $20 \mathrm{~mm}$ in diameter)

*It has been shown on many occasions that $\mathrm{Nb}$ alloys are most stable among all metallic materials under cavitation melt processing conditions in liquid aluminum (see References 11, pp. 314-320; 12, p. 641).

at a working frequency of $17.5 \mathrm{kHz}$ with a peak-to-peak amplitude of $40 \mu \mathrm{m}$.

The first experimental casting set-up was designed to observe the effect of USP at different stages of solidification in the permanent steel mold. Figure 1 shows a schematic of casting in this set-up. The starting melt temperature in the furnace was $1023 \pm 278 \mathrm{~K}$ $\left(750 \pm 5^{\circ} \mathrm{C}\right)$. The steel mold $70 \mathrm{~mm}$ in diameter and $200 \mathrm{~mm}$ in height was covered by insulating material from outside to minimize heat losses from the mold wall, while being placed on a thick steel plate to assure the progressive solidification from the bottom to the top. The sonotrode preheated to $873 \mathrm{~K}\left(600^{\circ} \mathrm{C}\right)$ was located at the top part of the mold, so that it would be submerged into the liquid metal by approximately $5 \mathrm{~mm}$ when the mold was filled with the melt. The molten metal (alloy 4.5Cu-1 from Table 1) was poured at $993 \mathrm{~K}$ $\left(720{ }^{\circ} \mathrm{C}\right)$. When the mold was completely filled, the ultrasonic transducer was turned on. Therefore, the metal at the bottom part of the mold was not subjected to USP (no USP, zone 4 in Figure 1). A clear transition between zones 4 and 3 is visible in the billet cross section. As the solidification progressed from the bottom towards the sonotrode, the solidifying alloy experienced action of ultrasound at different stages of solidification: first in the liquid phase only (zone 3), then (in the middle part of the mold) across the liquidus (zone 2), and finally in the mushy zone in the upper part of a billet (zone 1 in Figure 1). The boundaries between zones 1 and 3 are not strictly defined so this division is rather conditional. This mold provides a cooling rate of less than $1 \mathrm{~K} / \mathrm{s}$.

In the DC casting experiment, the ultrasonic melt treatment was applied in the hot top. The molten metal holding temperature, USP settings and equipment were the same as in the first set-up. The casting speed was 200 $\mathrm{mm} / \mathrm{min}$ and the billet diameter $80 \mathrm{~mm}$ with the maximum length of $450 \mathrm{~mm}$. The $4.5 \mathrm{Cu}-2$ (Table 1) alloy was poured at $993 \mathrm{~K}\left(720^{\circ} \mathrm{C}\right)$. The first half of the billet was solidified without USP (stage I in Figure 2); at 
Table I. Chemical Compositions of AA4032-Type Piston Alloys as Determined by Emission Spectrometry

\begin{tabular}{lcccccr}
\hline & \multicolumn{5}{c}{ Chemical Composition (Wt Pct) } \\
\cline { 2 - 7 } Alloys & $\mathrm{Si}$ & $\mathrm{Cu}$ & $\mathrm{Mg}$ & $\mathrm{Fe}$ & $\mathrm{Ni}$ & $\mathrm{Al}$ \\
\hline 4.5Cu-1 (Steel Mold) & 13.20 & 4.55 & 0.98 & 1.18 & 0.90 & bal. \\
4.5Cu-2 (Hot Top DC Casting) & 13.30 & 4.58 & 1.10 & 1.15 & 0.98 & bal. \\
\hline
\end{tabular}

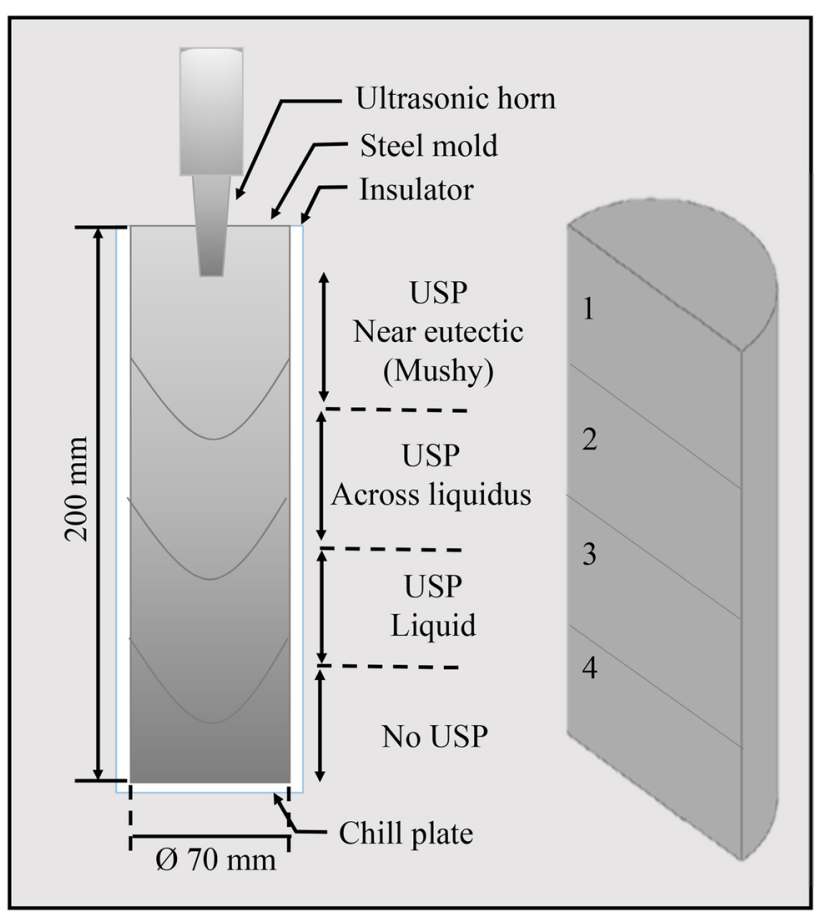

Fig. 1-A schematic diagram of experimental set-up for ultrasonic treatment at different stages of solidification in a permanent mold (showing different parts of the billet corresponding to different conditions of USP).

approximately 45 seconds after the casting started, which was about half of the maximum billet length, the ultrasonic transducer was switched on (stage II in Figure 2). A clear transition between the volumes of the billet not treated and treated with USP was visible in the billet cross section. Cooling rates during DC casting of such a small billet are well above $10 \mathrm{~K} / \mathrm{s}$.

The microstructures of each billet were examined along the vertical axis in the central portion of a billet (see Figure 1). In the case of permanent mold casting, zones 1 through 4 were examined including a no-US$\mathrm{P}-\mathrm{USP}$ transition. In the case of DC cast billets, as the liquidus and solidus isotherms (and the solidification front) are rather fixed in space during the DC casting, we only define three regions here, i.e., zone 1 as without USP, zone 2 as the transition between without USP and USP, and zone 3 as with USP (Figure 2).

Samples were ground and polished following standard procedures. Metallographic observations were made using optical microscopy (OM). The microstructure was observed along the centerline of the billets, corresponding to the areas that were affected by USP and

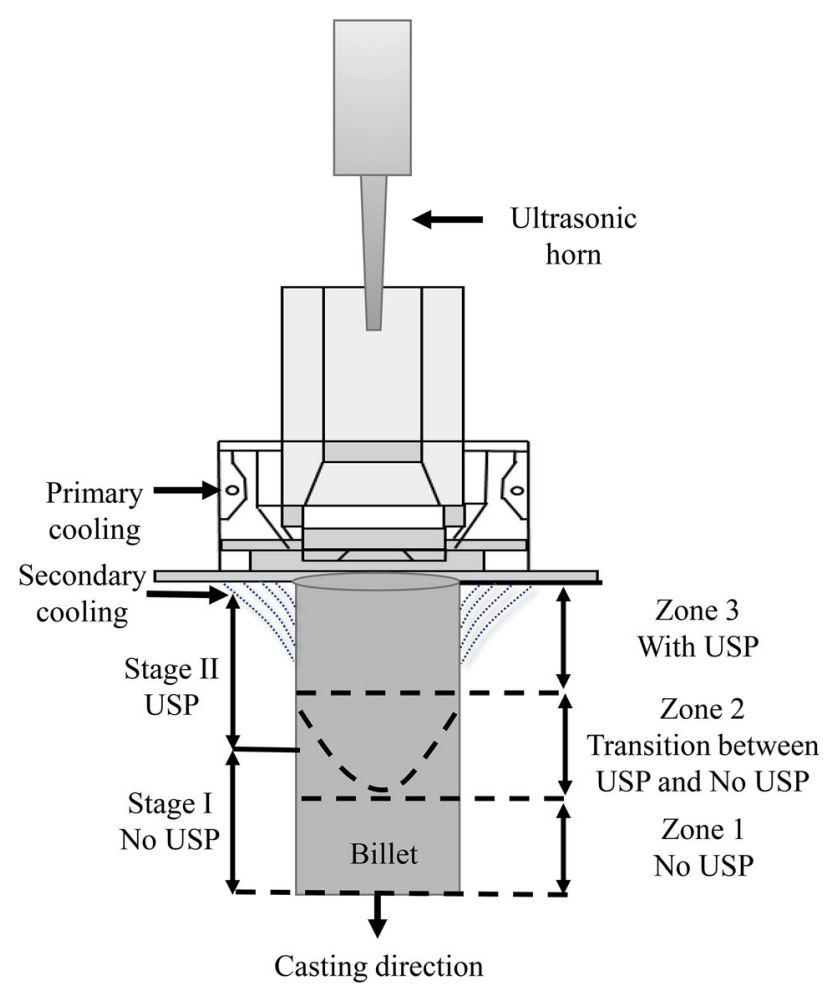

Fig. 2-Schematics of an experimental DC casting set-up with USP applied in the hot top (showing the different parts of the billet with different stages of casting, without (stage I) and with USP (stage II).

without USP as shown in Figures 1 and 2. The specimens were etched by Keller's reagent $(5 \mathrm{~mL}$ $\mathrm{HNO}_{3}, 3 \mathrm{~mL} \mathrm{HCl}$, and $2 \mathrm{~mL} \mathrm{HF}$ in $190 \mathrm{~mL}$ distilled water) for 20 seconds to clearly observe primary $\mathrm{Si}$ particles and intermetallic phases. The quantitative measurement of primary $\mathrm{Si}$ particles size and area fraction was carried out using ImageJ analysis software. The average values of parameters were obtained from 20 different images to represent the average values for each experimental condition. Furthermore, Fe-containing intermetallic phases were examined with a ZEISS Supra 35 scanning electron microscopy (SEM) with an energy dispersive spectroscopy (EDS) technique. In addition, polished samples were also anodized in Barker's solution ( 5 pet water solution of $\mathrm{HBF}_{4}$ ) for about 2 min at 20 VDC and were then examined under polarized light. The grain sizes were measured using the linear intercept method according to ASTM E112-10 and also the secondary dendrite arm spacing (SDAS) was determined by measuring the SDAS from the corresponding 
samples using the Image J analysis software with at least 30 measurements from 20 different images in each sample for both grain sizes and SDAS, and the average values were used to represent the grain sizes and SDAS. Additionally, an emission spectrometer was utilized to observe the chemical composition distribution along the centerline of the DC cast billet.

\section{RESULTS}

\section{A. Refinement of Primary Al Grains and Si Crystals}

Figure 3 shows typical micrographs illustrating the effect of USP on primary $\mathrm{Si}$ particles formed in a permanent mold (Figure 3(a) through (d)) and upon DC casting (Figure 3(e) and (f)). The quantitative analysis of the amount and sizes of primary Si crystals formed upon USP in different casting settings is given in Figure 4. In general, the results show the samples that were treated with ultrasonic oscillations have refined primary $\mathrm{Si}$ as compared to the non-USP ones, regardless of the casting technique. Also the amount of $\mathrm{Si}$ particles increases upon USP, especially when USP was performed below the liquidus. Primary Si crystals are more refined when USP was applied in the permanent mold as compared to the samples that were treated upon DC casting. The best result was achieved when USP was applied in the permanent mold in the liquid state (Figure 3(c)) with an average primary Si size of $35 \mu \mathrm{m}$. It is worth to note that the percentage of area ( 2 to $2.2 \mathrm{pct}$ ) and the size (110 to $127 \mu \mathrm{m}$ ) of primary Si were almost the same for no-USP conditions in the permanent mold or upon DC casting.
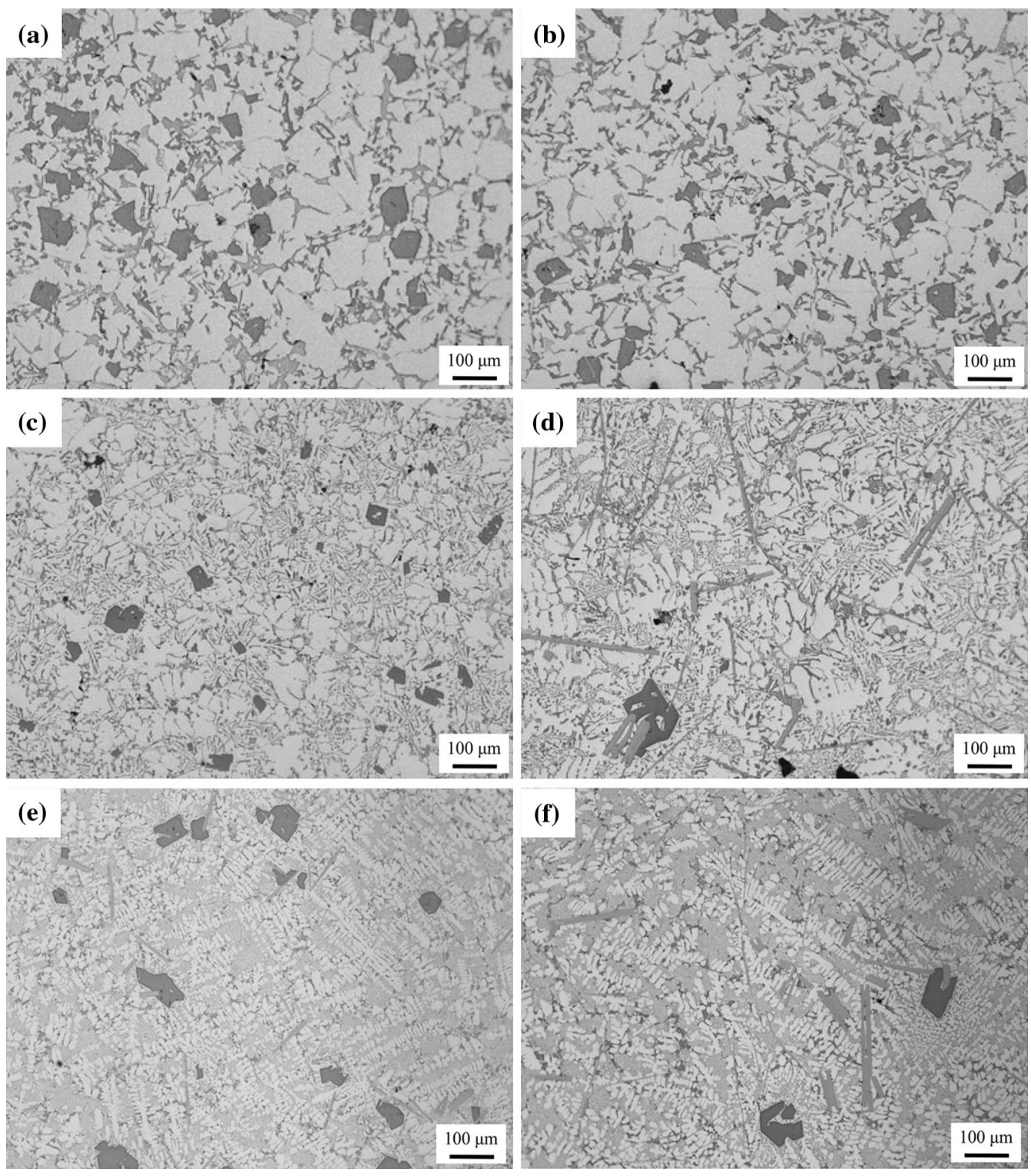

Fig. 3-The microstructures showing primary Si particles, intermetallics, and eutectics in the tested alloys cast in a permanent mold with USP at different stages of solidification: $(a)$ mushy, $(b)$ across the liquidus, $(c)$ liquid, and $(d)$ without USP; and during DC casting: $(e)$ USP in the hot top and $(f)$ no USP. 


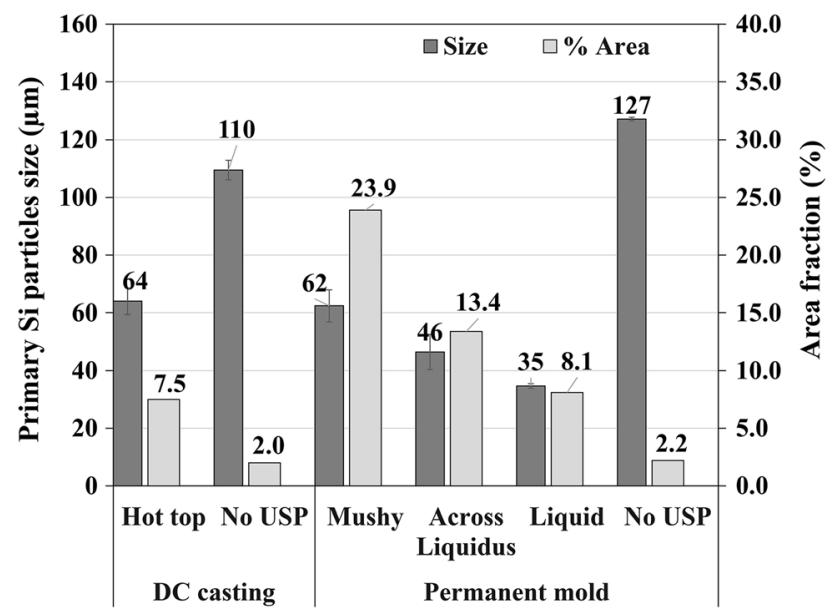

Fig. 4 -The amount and percentage area of primary Si particles in samples obtained under different casting conditions.

Figure 5(a) through (c) shows typical microstructures of anodized samples treated at different stages of solidification in the permanent mold, while Figure 5(e) and (f) shows the microstructures obtained upon DC casting. The major alloying element of our alloys is $\mathrm{Si}$, which is a disturbing element for anodizing. Thus, Si will precipitate in Al-matrix that shows as dark areas representing either the primary $\mathrm{Si}$ particles or the eutectic $\mathrm{Si}$ phases that were not fully anodized during anodizing. ${ }^{[21]}$ The quantitative analysis of the Al grain size obtained under different USP conditions is given in Figure 6. The results show USP results in grain refinement in all cases, but it is particularly pronounced upon USP in the permanent mold where the grain size decreases by a factor of 6 and more. The morphology of grains is also affected: dendritic grains are formed upon USP in the liquid state (Figure 5(c) and (e)), while as the solid fraction increases upon USP the grains acquire globular shape (Figure 5(a) and (b)).

The presence of dendritic grains allows us to analyze the cooling rate in the two casting set-ups. Figure 7 shows the data on SDAS that gives the SDAS of a sample cast in the permanent mold as approximately 2.5 times larger than the one cast in DC casting. This difference can be recalculated using the well-known expression $D=A V^{-0.33}$ to a 15 times difference in the cooling rates, which agrees well with our estimates of the cooling rate in the permanent mold as less than $1 \mathrm{~K} / \mathrm{s}$ while the cooling rate upon DC casting being in excess of $10 \mathrm{~K} / \mathrm{s}$.

\section{B. Refinement of Fe-Containing Intermetallics}

Optical micrographs in Figure 3 already show that the large needle-like particles of the $\beta$ (AlFeSi) phase are significantly refined by application of USP in the liquid stage, and also below the liquidus. The identification of these phases has been done in our previous work. ${ }^{[2]}$

Figure 8 shows the SEM images of the intermetallic particles formed under different casting conditions. The contrast makes it easier to see the $\beta$ phase (light gray particles). One can see that the typical morphology of the $\beta$-phase intermetallics in the sample produced without USP is needle-like (Figure 8(b) and (d)). USP applied to the liquid phase and especially across the liquidus is able to refine and modify the morphology of the intermetallics. In the permanent mold experiment, the morphology changes from needle-like (Figure 8(b)) into short rod-like (Figure 8(a)). In DC casting experiments, the morphology does not change but the elongated particles become shorter. The distribution of $\beta$-particle lengths with respect to the experimental conditions is given in Figure 9. USP reduces the average length of the particles two times in the case of mold casting and about 40 pct in the case of DC casting.

\section{Effect of USP on Eutectic Phases}

Figure 10 shows the effect of USP on eutectic phases at different experimental conditions. In both types of casting (permanent mold (Figure 10(c)) and DC casting (Figure 10(f))), the eutectic is finer and its apparent area fraction is higher upon casting without USP. However, the eutectic phase obtained through DC casting is more refined as compared to the sample from steel mold. The eutectic phase gradually coarsens with USP applied at progressively higher solid fraction (Figure 10(a), (b), and (d)). The coarsest eutectic was obtained upon USP in the mushy zone.

\section{Effect of USP on the Sump Profile and Macrosegregation}

Figure 11 shows the difference in the sump depth formed in the permanent mold and in DC casting as outlined by the transition line between treated/not treated parts of the billet. The sump in the permanent mold has a shallow profile with overall depth of $4 \mathrm{~cm}$ (distance from the sonotrode tip is $14 \mathrm{~cm}$ ), Figure 11(a). In DC casting, the sump profile is steeper, and the sump depth is $6 \mathrm{~cm}$ with the distance from the sonotrode tip 19 $\mathrm{cm}$, Figure 11(b). Figure 11(c) shows schematically the comparison between the directions of acoustic flow and natural convection flow. We can see that the acoustic flow is directed opposite to the natural convections flow in agreement with Reference 22. The sump profile is clearly outlined by the change in the structure and is shown by the red line.

Figure 12 shows the segregation of $\mathrm{Cu}$ across the diameter of the billets. According to the general macrosegregation theory, ${ }^{[23]}$ the direction of the segregation of all alloying elements with partition coefficient $K<1$ will be similar to some extent depending on the $K$ value. Thus, we do not analyze the segregation of other elements, e.g., $\mathrm{Si}, \mathrm{Mg}$, and $\mathrm{Fe}$ that have $K<1$. Both USP-treated and not USP-treated parts demonstrate typical negative centerline segregation. However, the application of USP (Figure 12(a)) clearly diminishes the extent of this segregation as compared to the not treated part (Figure 12(c)). Remarkably in the transition zone the centerline segregation turns to positive (Figure 12(b)).

Another interesting finding is shown in Figure 13 where elongated grains are observed at the bottom of 

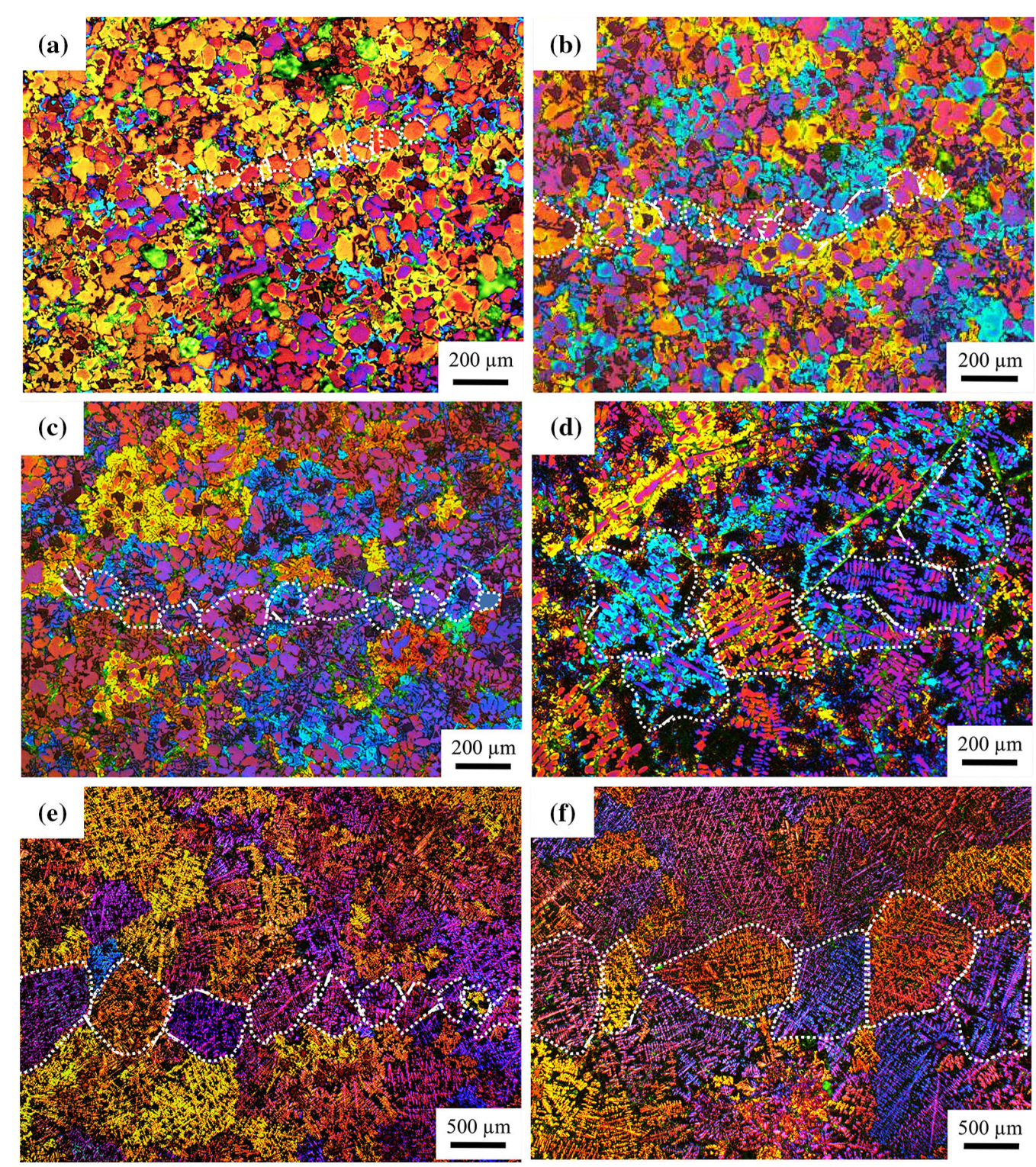

Fig. 5-Anodized micrographs showing the effect of USP on grain refinement upon different stages of solidification in the permanent mold: $(a)$ mushy, $(b)$ across the liquidus, $(c)$ liquid and $(d)$ without USP; and upon DC casting: $(e)$ USP in the hot top and $(f)$ no USP. To assist the reader in distinguishing the grains, some of the grain boundaries are outlined.
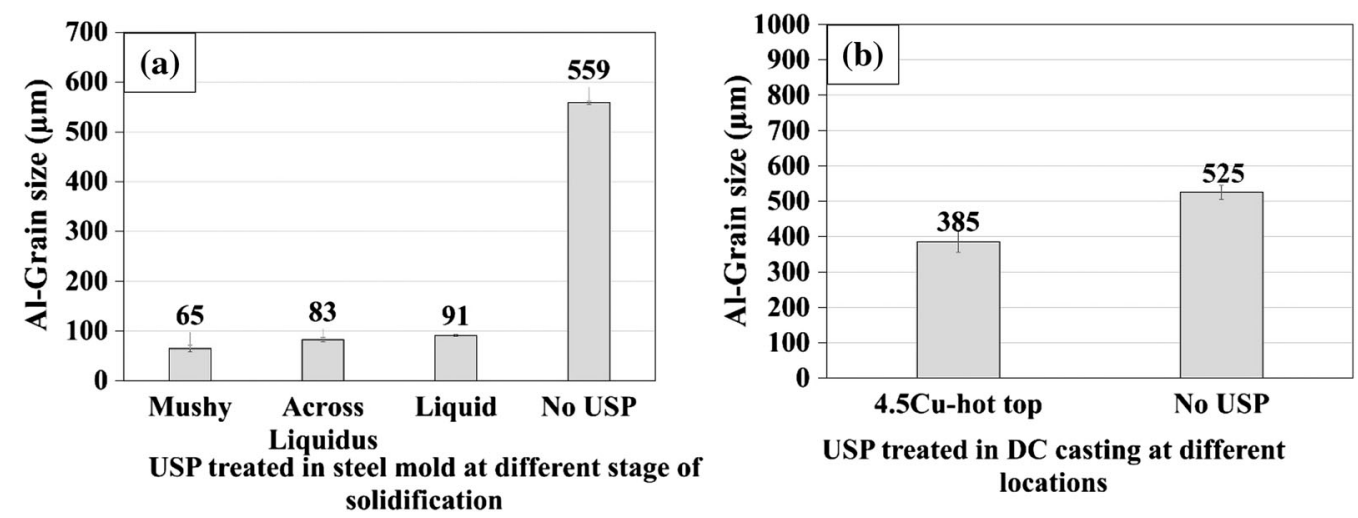

Fig. 6-The quantitative analysis of the grain size in the tested alloys with and without USP treatment: $(a)$ casting in the permanent mold and (b) DC casting. 
the sump in the transition area (just above the yellow line shown in Figure 13). We found that the direction of the elongated grain is towards the position of the sonotrode, which is the source of the acoustic flow.

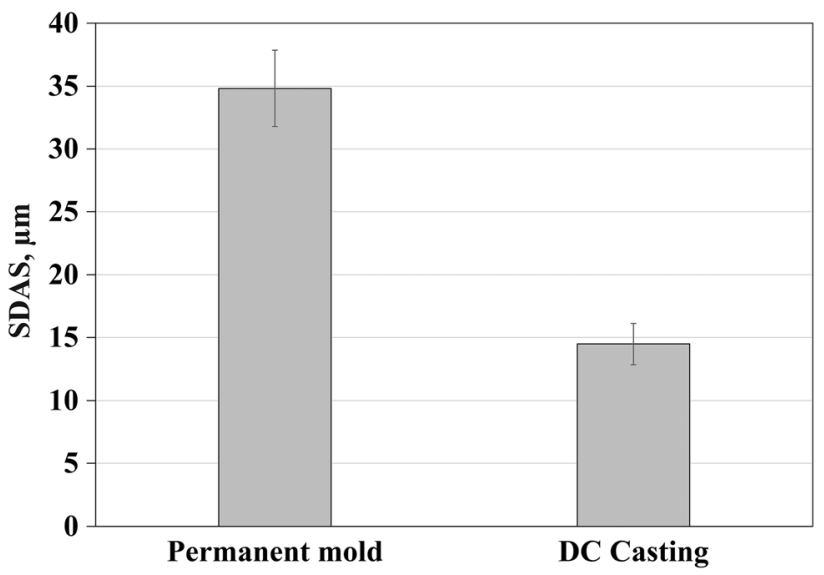

Fig. 7-Comparison of the secondary dendrite arms spacing (SDAS) in the billets produced by permanent mold casting and DC casting without USP.

\section{DISCUSSION}

The results show that there is a clear difference in the effects of USP on the structure depending on the stage of solidification where USP has been applied and on the casting process. This is a very important demonstration of the fact that the results reported in the literature cannot be directly compared if the experiments have been performed using different casting and solidification set-ups, and especially cannot be explained using the same mechanisms. It is also the reason why some effects observed in small-scale experiments (USP typically performed during solidification) cannot be directly reproduced in a large-scale casting (where USP is applied to the liquid phase or close to the liquidus). Also in DC casting, the modern attempts to repeat the successful grain refinement on industrial-scale billet in the works of Eskin and Eskin ${ }^{[1]}$ result in many cases in very marginal effects, ${ }^{[24]}$ which may be related to the use of different DC casting settings and mold design.

Let us look at the interpretation of the obtained results more closely.

\section{A. Microstructure Refinement and Modification}

When comparing the microstructure effects, it is logical to look first at the results obtained when USP was performed in the liquid or close to the liquidus in
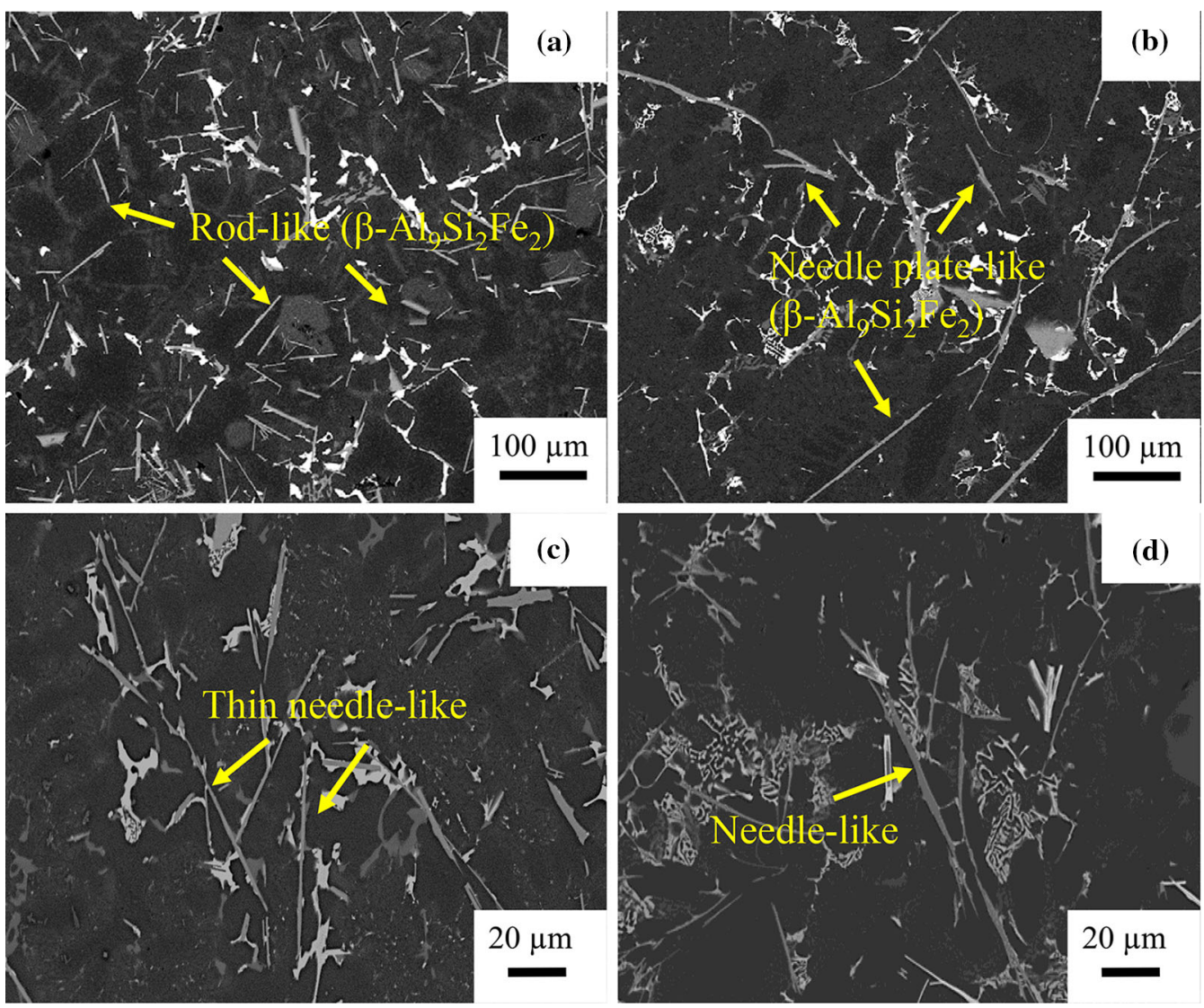

Fig. 8-Morphology of intermetallic particles in the tested alloys after USP in the permanent mold: $(a)$ across liquidus, $(b)$ without USP; and in DC casting: (c) USP in the hot top and $(d)$ without USP. 


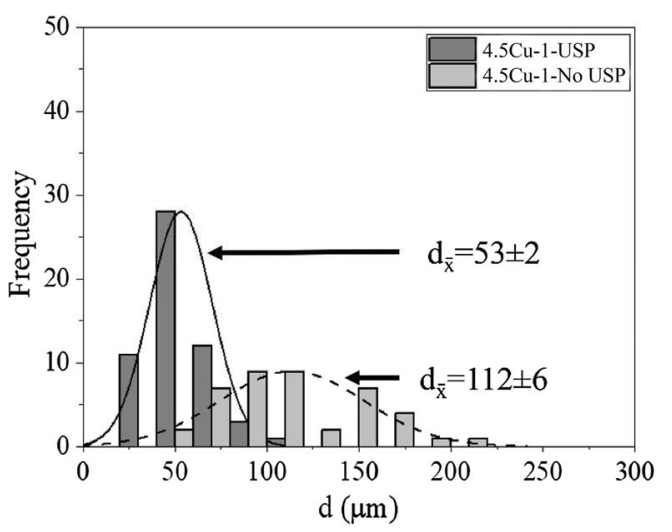

(a)

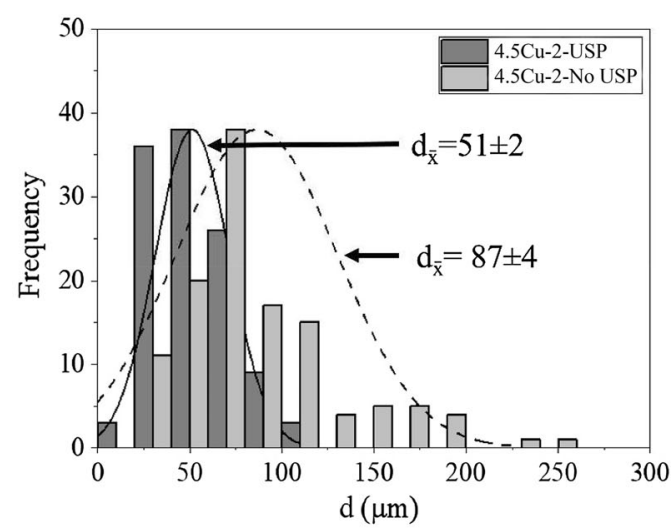

(b)

Fig. 9-Length distributions of Fe-containing intermetallics in samples with and without USP in $(a)$ in the permanent mold and $(b)$ in DC casting.
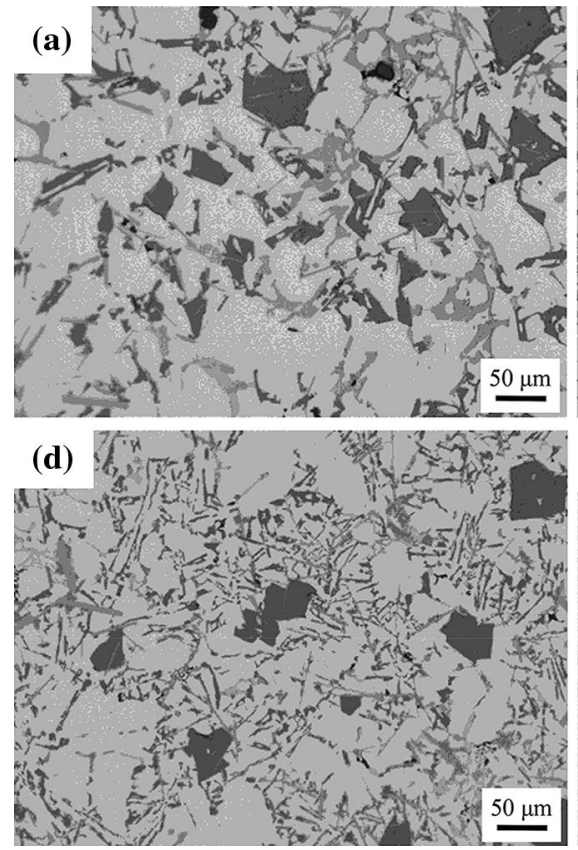

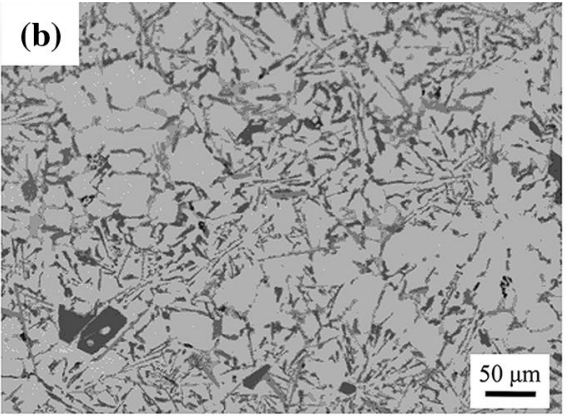

(e)

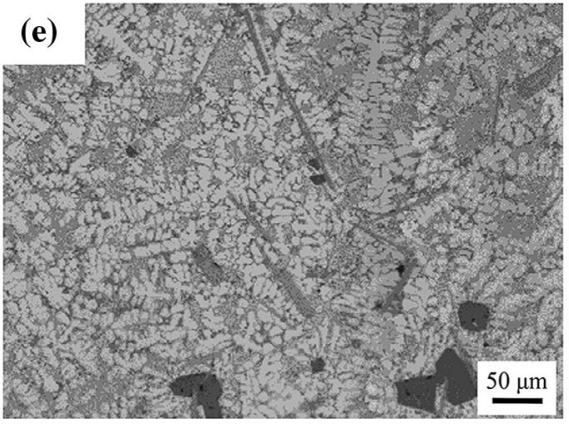

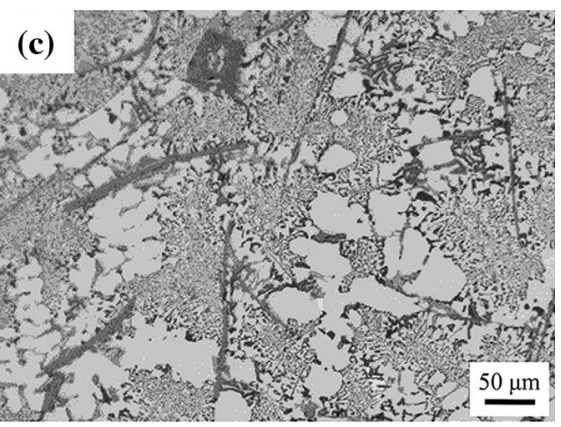

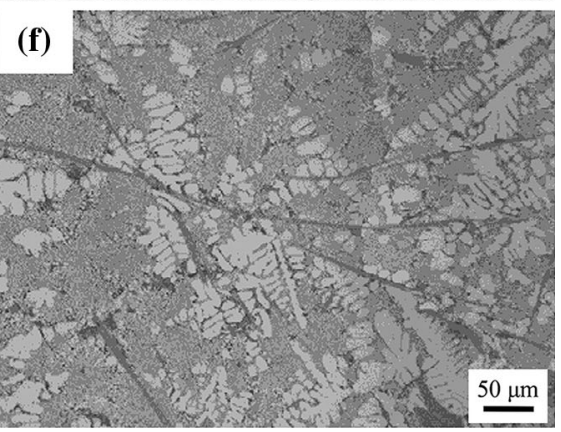

Fig. 10-Eutectic microstructure after USP in $(a)$ to $(d)$ the permanent steel mold: (a) mushy, (b) liquid, (c) no USP, (d) across the liquidus; and $(e, f)$ in DC casting: (e) USP, (f) no USP.

the permanent mold and compare those with the DC casting, where processing occurs at liquid and across liquidus stage without affecting the mushy zone. In both cases, USP results in the increase in the amount of primary $\mathrm{Si}$ and its refinement (Figures 3 and 4). The effects, however, are more pronounced in the permanent mold. We suggest that the ultrasonic cavitation facilitates nucleation of primary $\mathrm{Si}$ (hence more $\mathrm{Si}$ is observed upon USP) and also fragments Si particles multiplying them and preventing their excess growth. It seems that, as the cooling rate in DC casting is significantly larger than in the permanent mold (Figure 7), the Si particles should be more refined there. In fact the situation is opposite. In DC casting, the positions of the liquidus and solidus are rather fixed in space and a well-established circulation pattern exists in the sump, enabled by both thermal convection and acoustic streaming (see Reference 22 for details), while in the permanent mold the solidification front and the liquidus isotherms are constantly moving upwards. Therefore, despite the higher cooling rate, the time actually spent by the primary particles in the solidification domain may be longer in the case of DC casting (similar effect to so-called floating grains ${ }^{[25]}$ ). Therefore, despite the same increase of the amount of Si particles upon USP in both casting techniques due to the enhanced nucleation, the size of primary $\mathrm{Si}$ is larger in DC casting due to a longer time available for the growth. In the permanent mold, the size and the number of primary Si particles increases when the USP is applied to the semi-solid material 

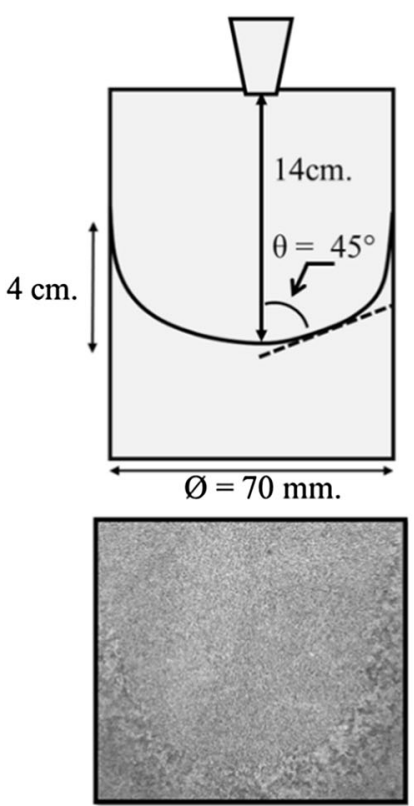

(a)
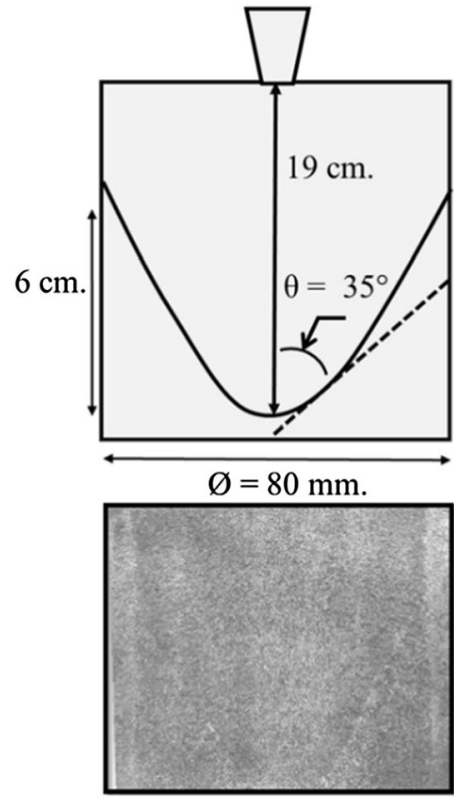

(b)

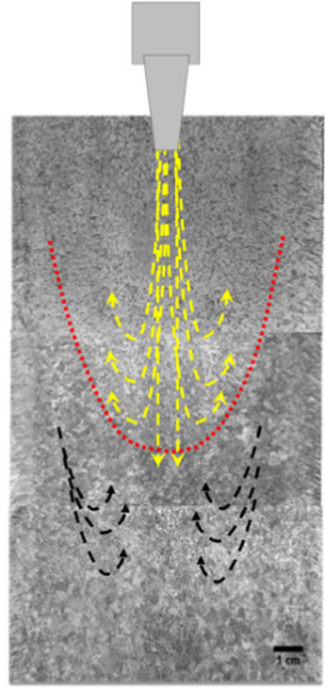

Acoustic flow

$\rightarrow$ Natural convection flow

(c)

Fig. 11-Effect of USP on the sump shape: $(a)$ in the permanent steel mold, $(b)$ in DC casting, and $(c)$ a scheme showing direction of convection with and without USP.

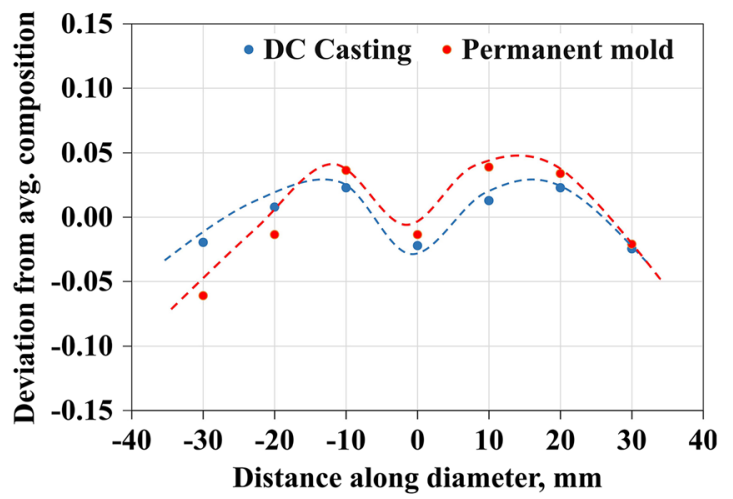

(a)

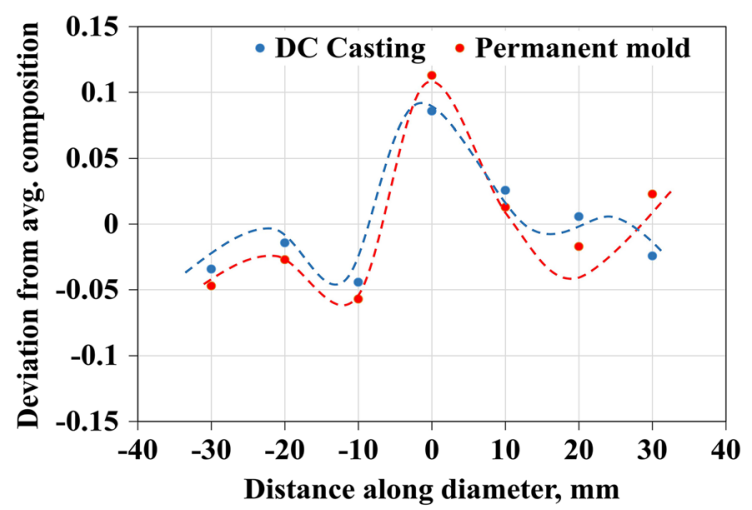

(b)

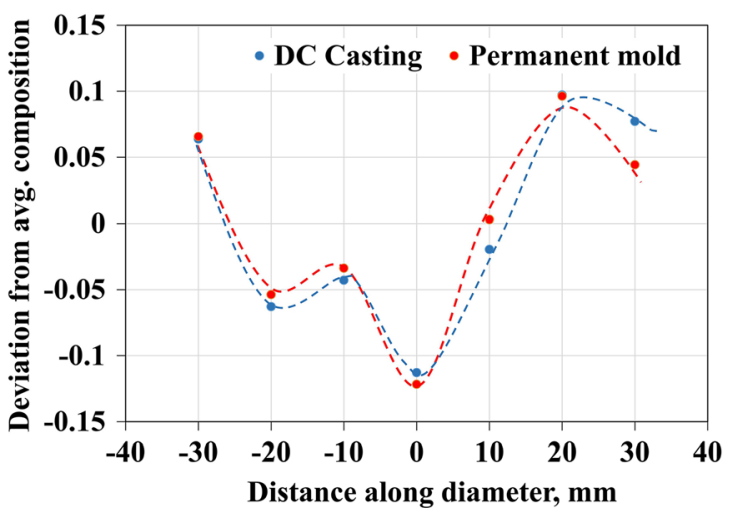

(c)

Fig. 12-Deviation from the average composition $(\mathrm{Cu})$ at three different zones in the permanent mold and DC casting $(a)$ USP, $(b)$ transition zone, and $(c)$ no USP. 


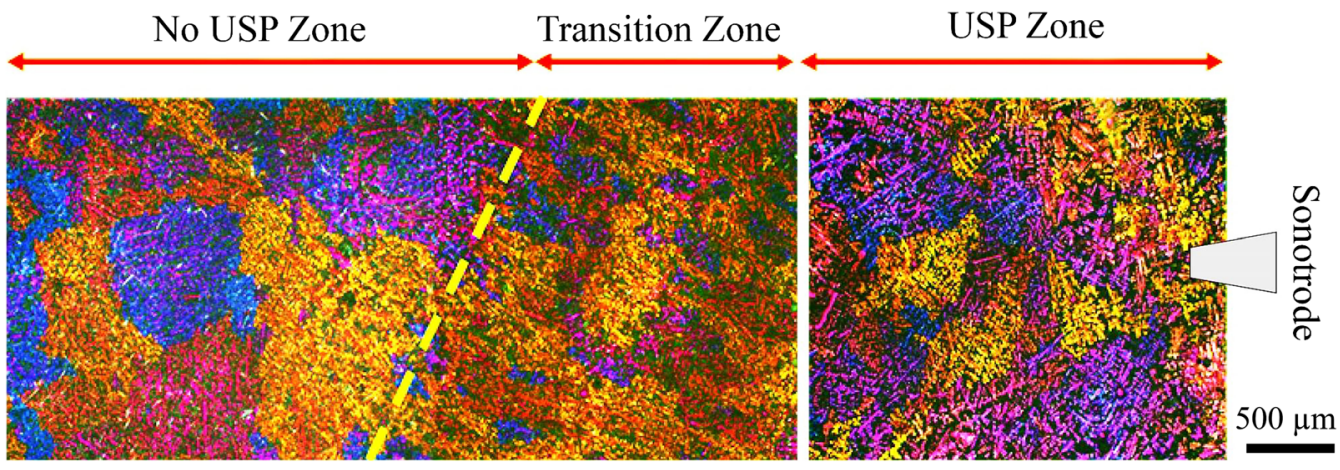

Fig. 13-Anodized micrograph of the billet subjected to USP. The dashed yellow line shows the transition zone between USP and no-USP zones (Color figure online).

(Figure 4), which demonstrates that the coarsening of $\mathrm{Si}$ crystals overtakes the refinement effect of their fragmentation by USP.

Similar trends are observed in modification of $\beta-\mathrm{Al}_{5} \mathrm{FeSi}$ particles as shown in Figures 8 and 9. These particles are formed as primary phases in the range of temperatures from $873 \mathrm{~K}$ to $888 \mathrm{~K}\left(600{ }^{\circ} \mathrm{C}\right.$ to $\left.615^{\circ} \mathrm{C}\right)$ to $853 \mathrm{~K}\left(580{ }^{\circ} \mathrm{C}\right)$ either directly for the melt or as a product of peritectic reaction with the $\delta(\mathrm{AlFeSi})$ phase $^{[26,27]}$ and, hence, are subjected to the same refinement mechanisms as primary Si. These results agree well with the reported refinement of the $\beta-\mathrm{Al}_{5} \mathrm{FeSi}$ particles upon USP performed in the temperature range $983 \mathrm{~K}$ to $958 \mathrm{~K}\left(710^{\circ} \mathrm{C}\right.$ to $\left.685^{\circ} \mathrm{C}\right),{ }^{[19]} 973 \mathrm{~K}$ to $883 \mathrm{~K}$ $\left(700{ }^{\circ} \mathrm{C} \text { to } 610{ }^{\circ} \mathrm{C}\right)^{[14]}$, or $973 \mathrm{~K}$ to $873 \mathrm{~K}\left(700{ }^{\circ} \mathrm{C}\right.$ to 600 $\left.{ }^{\circ} \mathrm{C}\right) .{ }^{[26]}$ The degree of intermetallic refinement is greater in the case of the permanent mold casting as the Fe-containing intermetallics formed in the alloy without USP are coarser there than in the case of DC casting (Figure 9). Thinner $\beta$-phase particles in the case of DC casting can be a result of a higher cooling rate, which agree with the earlier observations. ${ }^{[26]}$ In both casting techniques, the application of USP narrows the size distribution of the Fe-containing intermetallics around a smaller average length. We suggest that the fragmentation of the intermetallics is responsible for the observed effects. The fundamental mechanisms of fragmentation cannot be directly observed in our experiments as it would require high speed imaging combined with synchrotron radiation for liquid metals. These mechanisms have been studied elsewhere and confirm the essential role of cavitation bubble pulsation and implosion assisted by acoustic streaming. ${ }^{[28,29]}$

The overall coarsening of eutectics with USP is demonstrated in Figure 10. This effect is much more pronounced when USP is applied to the semi-solid alloy. In the permanent mold, when the USP was applied in the mushy zone, coarsened eutectic phase was observed in the microstructure. This phenomenon was previously reported. ${ }^{[30]}$ When applied to the semi-solid material, ultrasonic processing does not produce strong cavitation and acoustic streaming due to the rapid attenuation of the oscillations in the slurry medium and the confinement of the liquid phase (from which the eutectic is formed) to small pools between the grains. At the same time, the acoustic energy is still transferred to the semi-solid material, effectively heating it. ${ }^{[31]}$ As a result, the refining mechanism, i.e., fragmentation, does not work to a full extent while coarsening prevails due to the heating and the effectively decreased cooling rate.

Grain refinement is the effect of USP that is most reported and seemingly most studied (see reviews in References 11 and 12). It involves two main mechanisms: (a) enhanced heterogeneous nucleation either on wetted non-metallic inclusions or on fragmented suitable primary intermetallics and (b) fragmentation of dendrites. These two mechanisms are obviously acting in different temperature ranges. The results shown in Figures 5 and 6 demonstrate that the strong grain refinement was obtained upon USP in the permanent mold, while in DC casting the effect was moderate.

The studied alloy is a near-eutectic alloy with complex structure consisting of primary $\mathrm{Si}$, intermetallics, and $\mathrm{Al}$ dendrites and the majority of the structure formed as eutectic. Therefore, the effect of USP on enhancing the heterogeneous nucleation of the primary aluminum will be significantly diminished by the prior formation of $\mathrm{Si}$ and $\mathrm{Fe}$-containing phases and subsequent release of the latent heat. As this alloy does not contain additions of Al grain refiners (e.g., AlTiB) or special alloying elements that may form nucleating primary intermetallics (e.g., $\mathrm{Zr}$ ), the role of cavitation-enhanced nucleation appears to be not significant. This explains a marginal grain refining effect in DC casting. Note that the position of the sonotrode with respect to the liquidus isotherm may play an important role in grain refinement upon DC casting. Lowering the sonotrode may invoke fragmentation of dendrites from the slurry zone of the billet with their recirculation and redistribution by acoustic streaming as has been reported elsewhere. ${ }^{[22]}$ The position of the sonotrode with respect to the liquidus isotherm explains the strong grain refinement effect achieved in the permanent mold. In this case, the liquidus is constantly moving towards the sonotrode and the acoustic streaming efficiently interacts with the slurry zone, extracting the dendrites from there and transporting them upwards towards the sonotrode and the cavitation zone. Also the permanent mold has a smaller diameter than the DC cast billet, and thus the acoustic wave may have a stronger penetration 
throughout the casting volume, enhanced by the reflections from the walls and the solidification front. In the case of DC casting, the acoustic wave reflections are less pronounced as the sonotrode is located within the hot top (porous refractory material) that has absorbing rather than reflecting properties. For the grain refinement in our experiments, we suggest that the fragmentation mechanism enhanced by the acoustic streaming interaction with the semi-liquid slurry zone is responsible for the observed effects.

\section{B. Segregation and Sump Shape}

Figure 11 shows that the sump shape is different in the two casting settings used. The permanent mold billet has a shallower sump than the DC cast billet. There are two reasons for that. Firstly, the permanent mold provides a lower cooling rate as compared to the DC casting due to a lower heat extraction from the mold wall (thermally insulated $v s$ water cooled), which is corroborated by the measured dendrite arm spacing in Figure 7. Consequently, there is a lesser thermal gradient between the surface and the center of the billet in the permanent mold and, hence, a shallower and flatter sump. The second reason is in the amount of hot melt supply into the mold. In DC casting, hot melt is continuously fed into the hot top mold. Ultrasonic vibrations create an acoustic flow under the sonotrode that forces the hot melt along the centerline of the billet lowering the position of the liquidus and the solidification front in the sump (see a schematic in Figure 11(c)). This phenomenon was previously discussed elsewhere. ${ }^{22]}$ In the permanent mold, on the other hand, there is no continuous feeding of hot melt into the billet, and therefore the liquid temperature keeps decreasing as solidification progresses, resulting in flattening of the liquidus position in the sump and a flatter sump profile. Since the dominant mechanism for $\mathrm{Al}$ grain refinement in our experiments is dendrite fragmentation, the narrowing of the mushy zone in DC casting (due to the depression of the liquidus isotherm) reduces the effectiveness of this fragmentation mechanism, additionally contributing to a lesser grain refinement observed (see Figure 6).

The shape on the sump may have consequences for the macrosegregation, i.e., the macroscopic distribution of chemical composition. It is well known that the macrosegregation is governed by three main mechanisms: thermal-solutal convection, shrinkage-induced flow, and the transport of solid phase. ${ }^{[23]}$ A shallower sump should decrease an impact of the shrinkage-induced flow and floating grains and facilitate a higher concentration of alloying elements in the center of a billet, while the natural thermal-solutal convection brings the solute-rich liquid to the center but also takes them partially out of the center by the upward centerline flow (Figure 11(c)).

The acoustic flow produced by the sonotrode and directed downwards should oppose the thermal-solutal convective flow (upward in the center of a DC cast billet) and retain solute-rich liquid in the center of the billet (see a schematic in Figure 11(c)).
As the centerline segregation patterns are very similar, despite clearly different sump depths and steepness of the solidification front (Figures 11(a) and (b)), for both permanent mold and DC cast billets, the contributions of floating grains and shrinkage-induced flow to the macrosegregation are similar in both casting cases. What makes the difference is the convective flow and its direction. Without the USP, the distribution of $\mathrm{Cu}$ is governed mainly by natural convection. We can see that the centerline segregation is negative (Figure 12(c)), which means that the solutes brought in by the convective flow are also taken out by the upward flow. ${ }^{[32]}$ When the USP is switched on (the transition zone, Figure 12(b)), the forced acoustic flow from the sonotrode pushes the liquid down against the natural convection flow, which results in the instantaneous retention of the solutes in the center and positive centerline segregation. In addition, we also observed elongated grain structures in this area (Figure 13). The growth of these grains is directed towards the acoustic flow confirming its penetration into the slurry region of the billet. The hot liquid flow forced by the sonotrode and directed sideways in the central part of the billet increases the thermal gradient on the solidification front and also decreases the constitutional undercooling by washing out the solute build-up at the solidification front. Similar grain growth effects supported by computer simulations of acoustic streaming have been reported recently elsewhere. ${ }^{[22]}$ As the USP casting reached steady-state condition (USP zone), a relatively stable flow balance is re-established between the natural convection flow and the forced downward convection flow from sonotrode. This explains the relatively small negative centerline segregation and overall lesser macrosegregation across the billets' diameter for both casting cases studied (Figure 11(a)).

\section{CONCLUSIONS}

1. A casting technology and the stage of solidification where ultrasonic processing is applied dictate the selection of mechanisms acting and the efficiency of USP with regard to the structure refinement, modification, and macrosegregation. This is demonstrated by comparing the USP in a permanent mold where the solidification front progressively moves towards the source of ultrasound and the USP in $\mathrm{DC}$ casting where the solidification front is fixed in space with respect to the source of ultrasound.

2. The refinement of aluminum grains, primary $\mathrm{Si}$ particles, and intermetallics can be achieved when an Al-Si piston alloy is treated by ultrasound in the liquid stage (above liquidus) and across the liquids.

3. Ultrasonic melt processing of an Al-Si piston alloy promotes the formation of very small globular grains when applied during solidification (in the permanent mold) where the fragmentation mechanism works efficiently. The efficiency of USP for grain refinement during DC casting depends on the position of the sonotrode with respect to the liquidus isotherm. 
4. Ultrasonic melt processing of an Al-Si piston alloy results in the increased amount of primary Si via enhanced nucleation and refinement of these particles via fragmentation.

5. The fragmentation mechanism is responsible for the modification of $\beta$-phase morphology from needlelike to rod-like shape, with simultaneous refinement of the particles, which is most pronounced in the permanent mold casting.

6. The eutectic phases coarsen when USP is applied below the liquidus.

7. Acoustic streaming from the sonotrode promotes the transport of the solute-enriched liquid downward against the natural convection flow along the vertical billet centerline, which results in a decreased centerline segregation.

\section{ACKNOWLEDGMENTS}

The authors gratefully acknowledge King Mongkut's University of Technology Thonburi for funding Postdoctoral Fellowship to S.C., and the financial support from the "KMUTT 55th Anniversary Commemorative Fund" is also acknowledged by S.C. and C.L. D.E. acknowledges the financial support from EPSRC (UK) under Project UltraMelt2 (EP/R011001/1, EP/ R011044/1, and EP/R011095/1). S.C. gratefully acknowledges BCAST (UK) for hosting the research visit.

\section{OPEN ACCESS}

This article is licensed under a Creative Commons Attribution 4.0 International License, which permits use, sharing, adaptation, distribution and reproduction in any medium or format, as long as you give appropriate credit to the original author(s) and the source, provide a link to the Creative Commons licence, and indicate if changes were made. The images or other third party material in this article are included in the article's Creative Commons licence, unless indicated otherwise in a credit line to the material. If material is not included in the article's Creative Commons licence and your intended use is not permitted by statutory regulation or exceeds the permitted use, you will need to obtain permission directly from the copyright holder. To view a copy of this licence, visit https://crea tivecommons.org/licenses/by/4.0/.

\section{REFERENCES}

1. A. Hossain and A. Kurny: Chem. Met. Alloys, 2014, vol. 7, pp. $154-59$.
2. S. Chankitmunkong, D.G. Eskin, U. Patakham, and C. Limmaneevichitr: J. Alloys Compd., 2019, vol. 782, pp. 865-74.

3. L. Zuo, B. Ye, J. Feng, X. Kong, H. Jiang, and W. Ding: Mater. Sci. Eng. A, 2017, vol. 693, pp. 26-32.

4. N.A. Belov, D.G. Eskin, and N. Avxentieva: Acta Mater., 2005, vol. 53, pp. 4709-22.

5. G.H. Zhang, J.X. Zhang, B.C. Li, and W. Cai: Proc. Natl. Sci Mater., 2011, vol. 21, pp. 380-85.

6. A. Couture: Int. Cast. Met. J., 1981, vol. 6, pp. 9-17.

7. S.G. Shabestari: Mater. Sci. Eng. A, 2004, vol. 383, pp. 289-98.

8. Y. Zhang, J. Jie, Y. Gao, Y. Lu, and T. Li: Intermetallics, 2013, vol. 42, pp. 120-25.

9. N. Fatahalla, M. Hafiz, and M. Abdulkhalek: J. Mater. Sci., 1999, vol. 34, pp. 3555-64.

10. X.J. Wang, X. Cong, A. Muhammad, S. Hanada, H. Yamagata, and W.H. Wang: Trans. Nonferrous Met. Soc. China, 2014, vol. 24, pp. $2244-50$.

11. G.I. Eskin and D.G. Eskin: Ultrasonic Treatment of Light Alloy Melts, 2nd ed., Taylor and Francis, UK, 2015.

12. D.G. Eskin: Mater. Sci. Technol. (United Kingdom), 2017, vol. 33, pp. 636-45.

13. T.V. Atamanenko, D.G. Eskin, L. Zhang, and L. Katgerman: Metall. Mater. Trans. A, 2010, vol. 41, pp. 2056-66.

14. C.J. Todaro, M.A. Easton, D. Qiu, G. Wang, D.H. St. John, and M. Qian: Metall. Mater. Trans. A, 2017, vol. 48, pp. 5579-90.

15. N. Srivastava, G.P. Chaudhari, and M. Qian: J. Mater. Process. Technol., 2017, vol. 249, pp. 367-78.

16. J.G. Jung, S.H. Lee, Y.H. Cho, W.H. Yoon, T.Y. Ahn, Y.S. Ahn, and J.M. Lee: J. Alloys Compd., 2017, vol. 712, pp. 277-87.

17. H.K. Feng, S.R. Yu, Y.L. Li, and L.Y. Gong: J. Mater. Process. Technol., 2008, vol. 208, pp. 330-35.

18. X. Jian, T.T. Meek, and Q. Han: Scripta Mater., 2006, vol. 54, pp. 893-96.

19. H.R. Kotadia, M. Qian, D.G. Eskin, and A. Das: Mater. Des., 2017, vol. 132, pp. 266-74.

20. G. Wang, M.S. Dargusch, D.G. Eskin, and D.H. StJohn: Adv. Eng. Mater., 2017, vol. 19, p. 1700264.

21. S. Wernick, R. Pinner, and P.G. Sheasby: The Surface Treatment and Finishing of Aluminum and Its Alloys, 5th ed., Finishing Publications LTD, Teddington, 1987.

22. G.S.B. Lebon, G. Salloum-Abou-Jaoude, D.G. Eskin, I. Tzanakis, K. Pericleous, and P. Jarry: Ultrason. Sonochem., 2019, vol. 54, pp. 171-82.

23. R. Nadella, D.G. Eskin, Q. Du, and L. Katgerman: Prog. Mater Sci., 2008, vol. 53, pp. 421-80.

24. Z. Liu, R. Li, R. Jiang, L. Zhang, and X. Li: Metall. Mater. Trans. $A$, 2019, vol. 50, pp. 1146-52.

25. D.G. Eskin, J. Zuidema, V.I. Savran, and L. Katgerman: Mater. Sci. Eng. A, 2004, vol. 384, pp. 232-44.

26. Y. Osawa, S. Takamori, T. Kimura, K. Minagawa, and H. Kakisawa: Mater. Trans., 2007, vol. 48, pp. 2467-75.

27. T. Maitra and S.P. Gupta: Mater. Charact., 2002, vol. 49, pp. 293-11.

28. F. Wang, D.G. Eskin, J. Mi, C. Wang, B. Koe, A. King, C. Reinhard, and T. Connolley: Acta Mater., 2017, vol. 141, pp. $142-53$.

29. D. Shu, B. Sun, J. Mi, and P.S. Grant: Metall. Mater. Trans. A, 2012, vol. 43, pp. 3755-66.

30. A. Das and H.R. Kotadia: Mater. Chem. Phys., 2011, vol. 125, pp. 853-59.

31. T.V. Atamanenko, D.G. Eskin, and L. Katgerman: Proceedings of the 11th International Conference on Aluminium Alloys: Their Physical and Mechanical Properties; 22-26 Sept. 2008, Aachen, Germany. vol. 1, Wiley, Weinheim, pp. 316-20.

32. Q. Du, D.G. Eskin, and L. Katgerman: Mater. Sci. Eng. A, 2005, vols. 413-414, pp. 144-50.

Publisher's Note Springer Nature remains neutral with regard to jurisdictional claims in published maps and institutional affiliations. 